Noname manuscript No.

(will be inserted by the editor)

\title{
A Place-Based Analysis of Tornado Activity and Casualties in Shreveport, Louisiana
}

Tyler Fricker · Douglas L. Allen

Tyler Fricker

School of Sciences, University of Louisiana Monroe, Monroe, Louisiana, USA

E-mail: tfricker@ulm.edu

Douglas L. Allen

Department of Social Sciences, Emporia State University, Emporia, Kansas, USA

E-mail: dallen15@emporia.edu 


\begin{abstract}
Tornadoes are among the most violent hazards in the world capable of producing mass casualties. Much of what is known about the relationship between tornadoes and casualties - injuries and fatalities - is driven by quantitative methods that often omit individual community factors. In response, here we present a place-based analysis of tornado activity and casualties in Shreveport, Louisiana. Results show that tornado casualties are more likely in smooth and lower topography and in formally redlined neighborhoods. Results also indicate that areas around the local Barksdale Air Force Base have experienced fewer casualties than other parts of the city since the installation of a Doppler Radar in 1995 and that Shreveport has a greatly reduced casualty rate since the Super Outbreak of 2011. We argue that continued place-based approaches are necessary for an understanding of the multi-dimensional, structural, and historical legacies that produce disproportionate impacts to environmental hazards and that when combined with quantitative methods, place-based approaches have the potential to create regional-or-local intervention strategies that can reduce the loss of life.
\end{abstract}

Keywords Tornadoes, Casualties, Hazards, Physical Geography, Human Geography

\title{
Introduction
}

Tornadoes are intensively violent atmospheric hazards that pose an almost constant risk to human health and property in the United States. Nowhere in the world experiences more tornadoes than the United States, and as a result of this fact, no other country is faced with as intimate a relationship between humans and tornadoes. Physically, a tornado is little more than unstable air and water vapor in a rotating vortex. Weak tornadoes are powerful enough to cause damage to buildings and automobiles, while strong tornadoes have the ability to cause widespread damage, causing numerous injuries and fatalities. For example, in the April 25-28, 2011 tornado outbreak there were 324 death and 2906 injuries from 349 tornadoes according to data from the National Oceanic and Atmospheric Administration.

Much of what we know about the relationship between tornadoes and casualtiesinjuries and fatalities - is driven by quantifiable variables, often found through data from the decennial Census and the use of multiple regression models. Wind energy and population density explain a large portion of tornado casualties rates (Ashley et al., 2014; Fricker et al., 2017a; Elsner et al., 2018a), but so, too, do socioeconomic and demographic factors (Bohonos and Hogan, 1999; Simmons and Sutter, 2005, 2008, 2009; Ashley, 2007; Donner, 2007; Dixon and Moore, 2012; Lim et al., 2017). For example, Fricker et al. (2017a) find that a doubling of energy dissipation (i.e. wind energy) leads to a $33 \%$ increase in tornado casualty rates, while a doubling of population density leads to a $21 \%$ increase in tornado casualty rates. Simmons and Sutter $(2005,2008,2009)$ find that casualties increase with an increases in the percentage of mobile homes and Lim et al. (2017) find that casualties increase with an increase in the number of female-headed households.

Other knowledge about the relationship between tornadoes and casualties is driven by alternative methods, including mapping techniques and the creation of vulnerability indexes. Mapping the location of tornado casualties (Ashley, 2007; 
Fricker et al., 2017b) has provided insight into the spatial patterns of high casualty counts, which, historically, have occurred at the highest rates in the Mid-South and Southeast United States, while creation of vulnerability indexes like the Social Vulnerability Index (SoVI; (Cutter et al., 2003)) and the Socioeconomic and Demographic Vulnerability Index (SEDVI; (Strader and Ashley, 2018)) have provided broad-level understanding of factors that influence casualty rates. Both of these methods, however, can break down at finer scales (i.e. city- or town-level), leading Fricker and Elsner (2019) to suggest place-based or bespoken approaches to the tornado casualty problem. They argue that if the goal is to intervene-reduce the number of tornado casualties - in the tornado casualty problem, more care has to be taken to investigate individual community factors (e.g. labor displacements, history of mobile homes, redlining, etc.) that might explain why tornadoes are producing more casualties than we would otherwise expect (Fricker and Elsner, 2019).

One potential factor that is difficult to quantify in tornado casualty events is the belief in disaster-relate myths (Alexander, 2007) that may impact protective action decision making and sheltering practices. Prior research has found a large difference in the understanding of tornado risk between meteorologists and the general public (Hoekstra et al., 2011). More recently, Klockow et al. (2014) evaluates local placebased knowledge of "tornado myths" and misconceptions through an identification of "folk science" in the wake of the Super Outbreak of 2011 in Alabama and Mississippi. They find that local residents in tornado affected areas believe in the protective power of local waterways (e.g. Tennessee-Tombigbee Waterway), an increased vulnerability created by new roadway systems that flatten and lower elevation, and the protective power of hills. They also find that local residents believe in the power of near misses, where tornadoes impact people "there" but not "here." And while empirically it may be easy to assume that the local residents are simply misinformed, it is also likely that this "folk science" is built out of a place-based and culturally situated environmental knowledge that comes from living in one place for a long time (Klockow et al., 2014).

At the community level, there is a dearth of studies that focus on race/ethnicity and tornado casualties even in the face of a growing awareness related to tornado activity and impacts in the Mid-South and Southeast United States. The dearth presents an opportunity, however, to intervene before such studies perpetuate racial deficit model so common in many fields of research, such as education (Smit, 2012; McKay and Devlin, 2015; Davis and Museus, 2019). Deficit-thinking assumes historically marginalized communities lack or deficiency is the result of inequalities found facing their community. It is an academic version of "blaming the victim" by trying to figure out what they are doing wrong rather than interrogating what structural barriers/oppressions may exist. Rather than assuming resident lack of knowledge - whether in understanding warnings or the severity of tornadic activity in the region - or lack of preparedness, there is an opportunity for scholars to investigate structural issues that could explain the increased vulnerability of racially marginalized neighborhoods to casualty-producing tornadoes.

Environmental justice scholarship has shown how race and class are key factors in who suffers - and who benefits - from environmental hazards (Bullard, 1990; Smith, 2006; Bolin, 2007; Pulido, 2015). For example, Smith (2006) shows how Hurricane Katrina's impact on New Orleans, Louisiana was a product of social and political processes that occurred before and after the storm itself. Bullard 
(1990) argues that structural discrimination has "locked millions of people of color in polluted neighborhoods and hazardous low-paying jobs, making it difficult for them to... escape these health-threatening environments" (p.139).

Scholars have, more specifically, shown that formerly redlined areas - areas that experienced suppressed mortgage financing for people of marginalized racial, ethnic, and economic standing - in cities face increased environmental hazards risks. Hoffman et al. (2020) show that redlined areas across the United States have increased exposure to intra-urban heat impacts, Namin et al. (2020) show how tree canopy distribution and levels of air pollution within cities are connected to Home Owners' Loan Corporation's (HOLC) 1930s redlining map, and Grove et al. (2017) demonstrate that historical legacies of racial marginalization - segregation and redlining - have produced various environmental hazards for racially marginalized communities in Baltimore (e.g. environmental pollution, urban heat island effects, and vulnerability to flooding). These studies link historical legacies of discrimination to contemporary environmental burdens imposed upon racially and economically marginalized communities.

With this in mind, here we present a placed-based analysis of tornado activity and casualties in Shreveport, Louisiana. Our goal is to provide a detailed investigation of the tornado casualty landscape in Shreveport that can be used as a launching pad for more extensive regional analyses of tornado casualties. Furthermore, we seek to broaden the scope of data-driven statistical models for tornado casualties toward more theory-driven statistical models (Neyman, 1939; Box et al., 2005; Shmueli, 2010) in order to make them more responsible (Hand, 2019) by showing the importance of including local, place-based data to address causality rather than predictive power - or variance.

We provide a climatology of tornado frequency and tornado casualties in the city of Shreveport and compare tornado casualty rates across multiple physical and social systems with the hope of moving beyond relationships between quantifiable variables into more descriptive relationships that exist across space and time. More specifically, we evaluate tornado casualty rates in Shreveport over the underlying terrain, between the number and percentage of mobile homes, within the context of a colloquial understanding of "Dixie Alley" and the Barksdale Bubble - a weatherrelated myth known to local residents - and among HOLC residential security designations. Our work looks to add tornado casualties to the growing list of disparate impacts connected to historical practices of discrimination and aims to serve as a call for future research that interrogates the relationship between long-standing structural inequities and vulnerability to environmental hazardsparticularly tornado casualties.

\section{Study Area and Data}

Shreveport is a city in northwest Louisiana (Fig. 1). It is the third largest city in the state - behind Baton Rouge and New Orleans - and is the most populous in the Shreveport-Bossier City Metropolitan area. As of 2019, Shreveport had an estimated population of 186,815 people, including 75,620 households (U.S. Census Bureau, 2019a). The demographic and socioeconomic profile of Shreveport suggests that the city is predominately black, female, and lesser-educated, with a low household median income and high rates of poverty across all age groups (Table 1). 
Fig. 1 Study area: Shreveport, Louisiana. The red circle is representative of a $30 \mathrm{~km}(\sim 20$ mile) radius around the city Centroid.

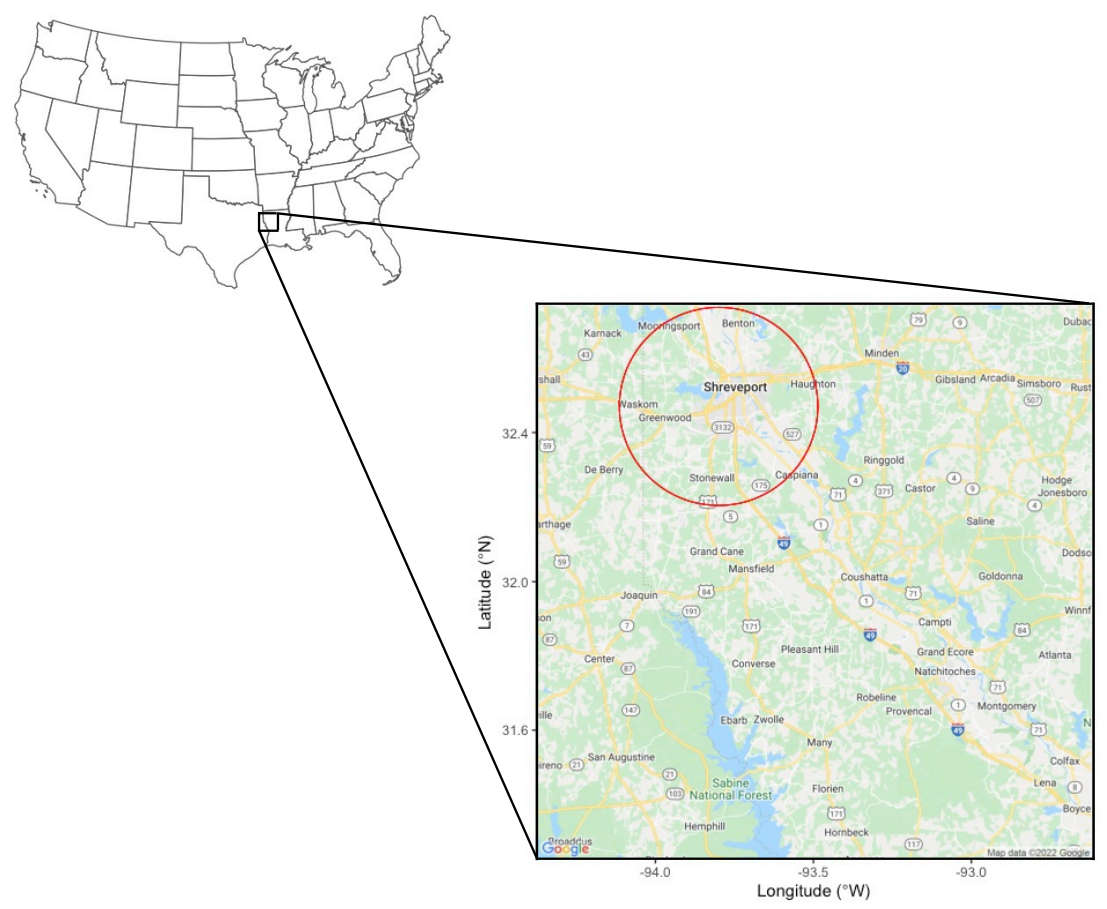

Tornado reports are obtained from the Storm Prediction Center's (SPC) historical tornado database (https://www.spc.noaa.gov/gis/svrgis/), which is compiled by the National Weather Service (NWS) Storm Data and reviewed by the National Centers for Environmental Information (NCEI) (Verbout et al., 2006). Reports include information on the date, time, location, damage characteristics, and maximum damage rating from 0 to 5 (Fujita (F) Scale prior to February 2007 and EF Scale thereafter), as well as the number of injuries and deaths directly attributed to each tornado. Only those tornadoes intersecting the immediate area of Shreveport - here, $30 \mathrm{~km}$ - are considered (Fig. 1). Population and mobile home data are collected from the U.S. Census Bureau and American Community Survey at the census tract level. Elevation is obtained from a digital elevation model as a georeferenced tagged image file (TIF; http://www.viewfinderpanoramas.org/ DEM/TIF $15 /)$ at 3 arc second resolution $(\sim 80 \mathrm{~m})$ with an accuracy of $\pm 7 \mathrm{~m}$ per pixel.

\section{Shreveport Tornado Climatology}

Over the period 1950-2019, Shreveport has been impacted by 108 tornadoes, corresponding to an annual rate of 1.5 tornadoes per year. Like many Mid-South 
Table 1 Demographic and socioeconomic profile of Shreveport, Louisiana. Data are collected from the American Community Survey (U.S. Census Bureau, 2019a,b). Demographic and socioeconomic categories are highlighted in bold.

\begin{tabular}{lcc}
\hline & Total & Percentage \\
\hline Age & & \\
Under 18 & 44,259 & $23.7 \%$ \\
$18-44$ & 67,127 & $35.9 \%$ \\
$45-64$ & 44,443 & $23.8 \%$ \\
65 and Over & 30,986 & $16.6 \%$ \\
\hline Sex & & \\
Male & 87,394 & $46.8 \%$ \\
Female & 99,421 & $53.2 \%$ \\
\hline Race & & \\
White & 71,194 & $38.1 \%$ \\
Black or African American & 108,150 & $57.9 \%$ \\
American Indian and Alaska Native & 787 & $.40 \%$ \\
Asian & 2,633 & $1.4 \%$ \\
Other (including two or more races) & 4,051 & $2.2 \%$ \\
\hline Educational Attainment (25 Years and Over) & & \\
High School Graduate or Higher & 107,335 & $86 \%$ \\
Bachelor's Degree or Higher & 31,434 & $25.2 \%$ \\
Graduate or Professional Degree & 12,364 & $9.9 \%$ \\
\hline Income & & \\
Household Median Income & $\$ 45,013$ & \\
Per-Capita Median Income & $\$ 25,255$ & \\
\hline Poverty & \multicolumn{2}{l}{} \\
Total Population & 42,775 & $22.9 \%$ \\
Children (Under 18) & 17,954 & $40.5 \%$ \\
\hline
\end{tabular}

and Southeast cities, Shreveport has been impacted by a wide range of tornadoes with individual damage path dimensions and intensities (Table 2). The February 12, 1950 tornado had a length of $132 \mathrm{~km}$, which is the $92^{\text {nd }}$ longest tornado in the historical record and in the $99^{t h}$ percentile of the same record. The May 16, 2013 tornado had a width of $1 \mathrm{~km}$, which is in the $99^{t h}$ percentile of the historical record. The March 10, 1952 tornado had an estimated tornado power of 4.2 terawatts $(\mathrm{TW})$, which is among the most powerful tornadoes in the historical record ( $99^{t h}$ percentile) and one of the top 5 most powerful tornadoes to impact the state of Louisiana. Only three tornadoes (02-12-1950, 04-03-1999, and 12-031978) were determined to be a violent tornado (EF-rating $\geq 4$ ), with no EF5 tornadoes on record. Still, when compared to the national average, tornadoes impacting Shreveport are over twice (2.2) as long, 1.5 times as wide, and 2.6 times as powerful.

Table 2 Statistical summary of Shreveport tornado characteristics.

\begin{tabular}{|c|c|c|c|c|c|c|}
\hline Variable & Minimum & $25^{t h}$ Percentile & Median & Mean & $75^{t h}$ Percentile & Maximum \\
\hline Path Width (m) & 1 & 30 & 72 & 134 & 144 & 1000 \\
\hline Path Length (km) & .02 & .69 & 3.44 & 12.3 & 12.9 & 132 \\
\hline Tornado Power (GW) & .01 & .94 & 1.02 & 24.5 & 9.6 & 4210 \\
\hline EF Scale (Maximum Rating) & 0 & 1 & 1 & 1.3 & 2 & 4 \\
\hline
\end{tabular}


Due to the quality of the historical record, further evaluation of the tornado climatology of Shreveport can be made by year, month, and hour of occurrence. By year, 1990 stands out as the most active tornado season to impact Shreveport with 14 recorded tornadoes. The next closest year is 2009 with 7, followed by 1965 and 2019 with 6 tornadoes, each. Unsurprisingly, then, the 1990s were the most active decade with respect to tornado impacts in Shreveport with 26 total tornadoes, followed by the 2010s with 22, the 1980s with 20, and the 1960 s with 14 . When subset by decade, there appears to be an increasing trend in the number of tornadoes with the last three decades averaging 10 more tornadoes (20) than the first three decades (10). April produced the highest number of tornadoes with 37, followed by May with 18, and February with 13. June (3), July (2), and August (1) produced the fewest tornadoes. This large shift in seasonality of tornado occurrence in Shreveport can largely be explained by the migrating low-level jet, proximity to the Gulf of Mexico, and the yearly change in physical environments conducive to tornadoes (Brooks et al., 2003; Weaver et al., 2012; Bluestein, 2013; Molina et al., 2016). Most tornadoes (57) that impact Shreveport occur during the day (6:00am-5:59pm Central Standard Time (CST)), though the evening hours (6:00pm-11:59pm CST) also produce many tornadoes (43). Given its geographic location, Shreveport is less likely to be impacted by tornadoes (8) at night (12:00am-5:59am CST) than other Mid-South cities (e.g. Memphis, Tennessee).

Of specific interest to this work is the tornado casualty climatology of Shreveport. Over the same 70-year period, Shreveport has been impacted by 22 casualtyproducing tornadoes resulting in 683 casualties with 29 fatalities and 654 injuries. When considering all casualty-producing tornadoes, the per-tornado casualty rate is 31 , with a per-tornado fatality rate of 1.3 , and a per-tornado injury rate of 30 . This per-tornado casualty rate is 2.4 times the national average, while this pertornado fatality rate and per-tornado injury rate is 1.7 and 2.4 times the national average, respectively. When considering all tornadoes, the per-tornado casualty rate is 6.3 , with a per-tornado fatality rate of .27 and a per-tornado injury rate of 6.1. This per-tornado casualty rate is nearly 4 times national average, while this per-tornado fatality rate and per-tornado injury rate is 3 and 4 times the national average, respectively. Thus, under any definition of the tornado casualty rate, Shreveport is well above the national average with respect to the number of casualties per tornado.

As a means of investigating whether tornado casualties follow the same patterns as tornado frequency in Shreveport, we evaluate the number of casualties by year, month, and hour of occurrence. By year, 1978 has the highest number of casualties with 282, followed by 1987 with 117 casualties, 1999 with 110 casualties, and 1950 with 95 . Only six of the 70 years resulted in 10 or more casualties, with a yearly average of 9.8 casualties. When broken down by decade, it is clear that the number of casualties is decreasing with time. From 1950-1979, the average decadal (10-year) casualty rate was 130, while from 1990-2019, the average decadal casualty rate was 55 . Reasons for this decline are likely some combination of improved severe weather detection and warning and luck - tornadoes not impacting densely populated areas of the city (Ashley, 2007; Simmons and Sutter, 2011; Fricker et al., 2017a). Cold-season tornadoes are the most destructive-from a human perspective - in Shreveport with December resulting in the highest number of tornado casualties at 268, followed by April (141), November (117), and February (105). By time of day, nighttime tornadoes result in the highest number 
of casualties with 270 , followed by daytime and evening tornadoes with 261 and 152 , respectively. At the per-tornado level (when considering all tornadoes), tornadoes at night have an extremely high casualty rate of 34-driven primarily by one tornado that caused 268 casualties - followed by tornadoes during the day with a casualty rate of 4.6 and tornadoes during the evening with a casualty rate of 3.5. As a relative proportion of all tornadoes, those impacting Shreveport at night $(25 \%)$ are more likely to result in a casualty than those during the day $(21 \%)$ or those during evening (19\%). Reasons for the high casualty rate and the larger proportion of casualty-producing tornadoes at night is almost assuredly a combination of factors, including difficulty in visually identifying a tornado on the ground, difficulty in warning individuals of a tornado, the daily patterns of people - who are often sleeping at night - and public risk perception (Ashley et al., 2008; Mason et al., 2018; Ellis et al., 2020; Krocak et al., 2021; Fricker and Friesenhahn, 2021).

To situate the tornado landscape of Shreveport to other cities in the Mid-South or Southeast, tornado frequency and tornado casualties are compared to seven other nearby cities: (1) Baton Rouge, Louisiana, (2) Dallas, Texas, (3) Houston, Texas, (4) Jackson, Mississippi, (5) Little Rock, Arkansas, (6) Memphis, Tennessee, and (7) Monroe, Louisiana. When evaluated alongside these other cities, Shreveport stands out amongst the most active and casualty prone areas in the region (Table 3). Combined with information on tornado occurrence and casualty rates throughout the country, it is clear that while Shreveport may not be the most impacted city in the Mid-South or Southeast with respect to tornadoes and their destructive potential, it is still amongst the most vulnerable cities in the country to devastating tornado events.

Table 3 Tornado frequency and casualties in Mid-South and Southeast cities ranked by casualty rate. Shreveport, Louisiana statistics are highlighted in bold.

\begin{tabular}{|c|c|c|c|c|}
\hline City & Number of Tornadoes & Annual Frequency Rate & Number of Casualties & Casualty Rate \\
\hline Dallas, TX & 114 & 1.62 & 1017 & 8.92 \\
\hline Little Rock, AR & 114 & 1.62 & 885 & 7.76 \\
\hline Jackson, MS & 150 & 2.14 & 1103 & 7.35 \\
\hline Shreveport, LA & 108 & 2.54 & 683 & 6.32 \\
\hline Memphis, TN & 71 & 1.01 & 381 & 5.37 \\
\hline Houston, TX & 157 & 2.24 & 315 & 2.00 \\
\hline Baton Rouge, LA & 73 & 1.04 & 120 & 1.64 \\
\hline Monroe, LA & 62 & .89 & 82 & 1.32 \\
\hline
\end{tabular}

\section{Potential Factors Related to Tornado Casualties}

Terrain

Tornado frequency is often driven, in some part, by the underlying landscape (Bluestein, 2000; Dunn and Vasiloff, 2001; Prociv, 2012). Previous work shows a decrease in the number of tornadoes with an increase in topographic variability across much of the Eastern United States (Karpman et al., 2013), fewer tornadoes in Kansas counties with greater elevation variation (Jagger et al., 2015), and more tornadoes in areas with uniform elevation relative to areas with variable elevation (Elsner et al., 2016). The physical explanation for these results is most likely 
connected to inflow, where smoother and lower topography allows for increased tangential velocity, while rougher and higher topography reduces the tangential velocity (Lewellen, 1962; Davies-Jones, 1973; Leslie, 1977). Simply put, smoother and lower topography is more conducive to air inflow that produces tornadoes than rougher and higher topography. To evaluate whether terrain influences the frequency of tornadoes - or more importantly for this work, casualty-producing tornadoes - in Shreveport, we compare tornado counts to values of elevation and terrain roughness.

We begin with a domain $92^{\circ}$ and $95^{\circ} \mathrm{W}$ longitude and $31^{\circ}$ and $33^{\circ} \mathrm{N}$ latitude (Fig. 2). Next, a grid at a spatial resolution of $.15^{\circ}$ latitude and longitude is applied, resulting in 13 cells in the north-south direction and 20 cells in the east-west direction (260 total cells). This resolution was chosen as a compromise between too fine and too course, and to allow for several tornado paths to intersect the majority of cells. Tornado paths are placed onto the grid and the number of paths that intersect each cell are counted (Fig. 3). There are 779 tornadoes - up from 108 Shreveport-area tornadoes - that intersect the domain, which results in an average of 2.99 tornadoes per cell. The maximum number of tornadoes impacting any one cell is 26 and the minimum number of tornadoes impacting any one cell is 0 (2 cells).

Fig. 2 Satellite imagery of the domain. Tornado paths are shown in gray. Shreveport is highlighted as a black point. The black line represents the political boundary between Louisiana and Texas.

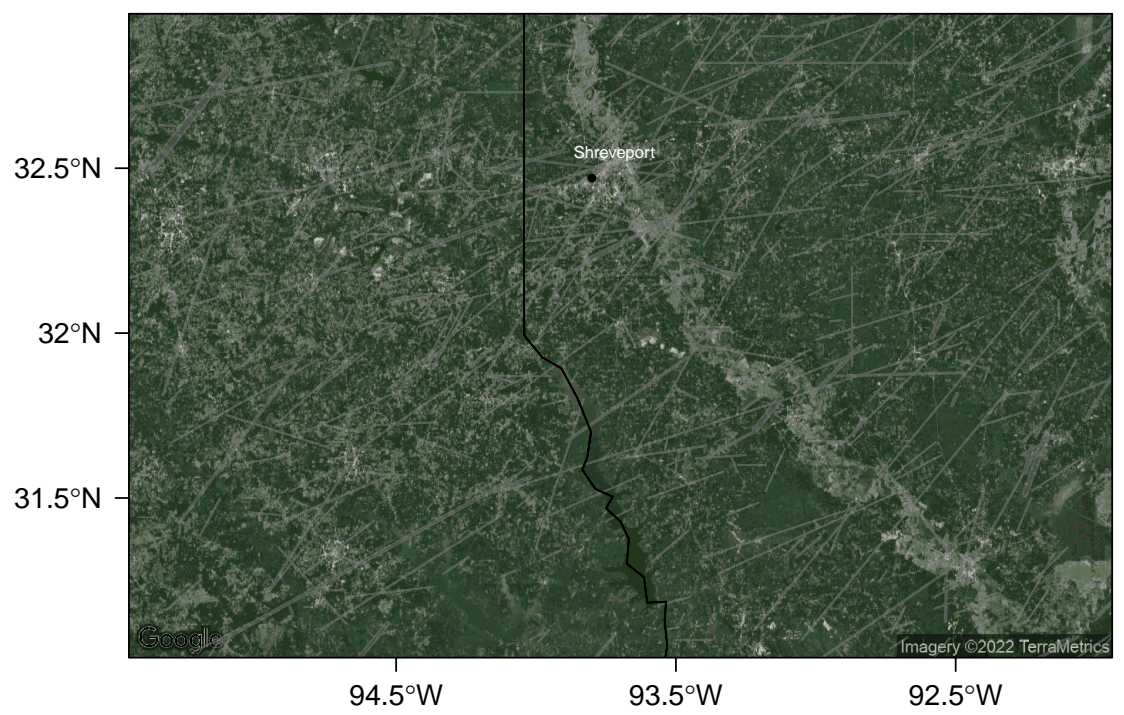

In addition to the number of tornadoes, we calculate elevation and elevation roughness per cell in the domain (Fig. 3). The $80-\mathrm{m}$-pixel elevation raster is cropped to the extent of the domain, and elevation roughness is computed as the largest difference in elevation in a pixel relative to the elevation in the eight 
neighboring pixels (Elsner et al., 2016). The average elevation of a cell in the domain is $68.7 \mathrm{~m}$ with a maximum of $149 \mathrm{~m}$ and a minimum of $12.6 \mathrm{~m}$. The average elevation roughness of a cell in the domain is $12.6 \mathrm{~m}$ with a maximum of $25.4 \mathrm{~m}$ and a minimum of $1.10 \mathrm{~m}$.

Fig. 3 Tornado counts (top-left), tornado casualties (top-right), elevation (bottom-left), and elevation roughness (bottom-right) of the domain. Elevation is height measured in meters. Elevation roughness is the largest difference elevation between a cell and the elevation in neighboring cells measured in meters. Shreveport is highlighted as a black point. The black line represents the political boundary between Louisiana and Texas.
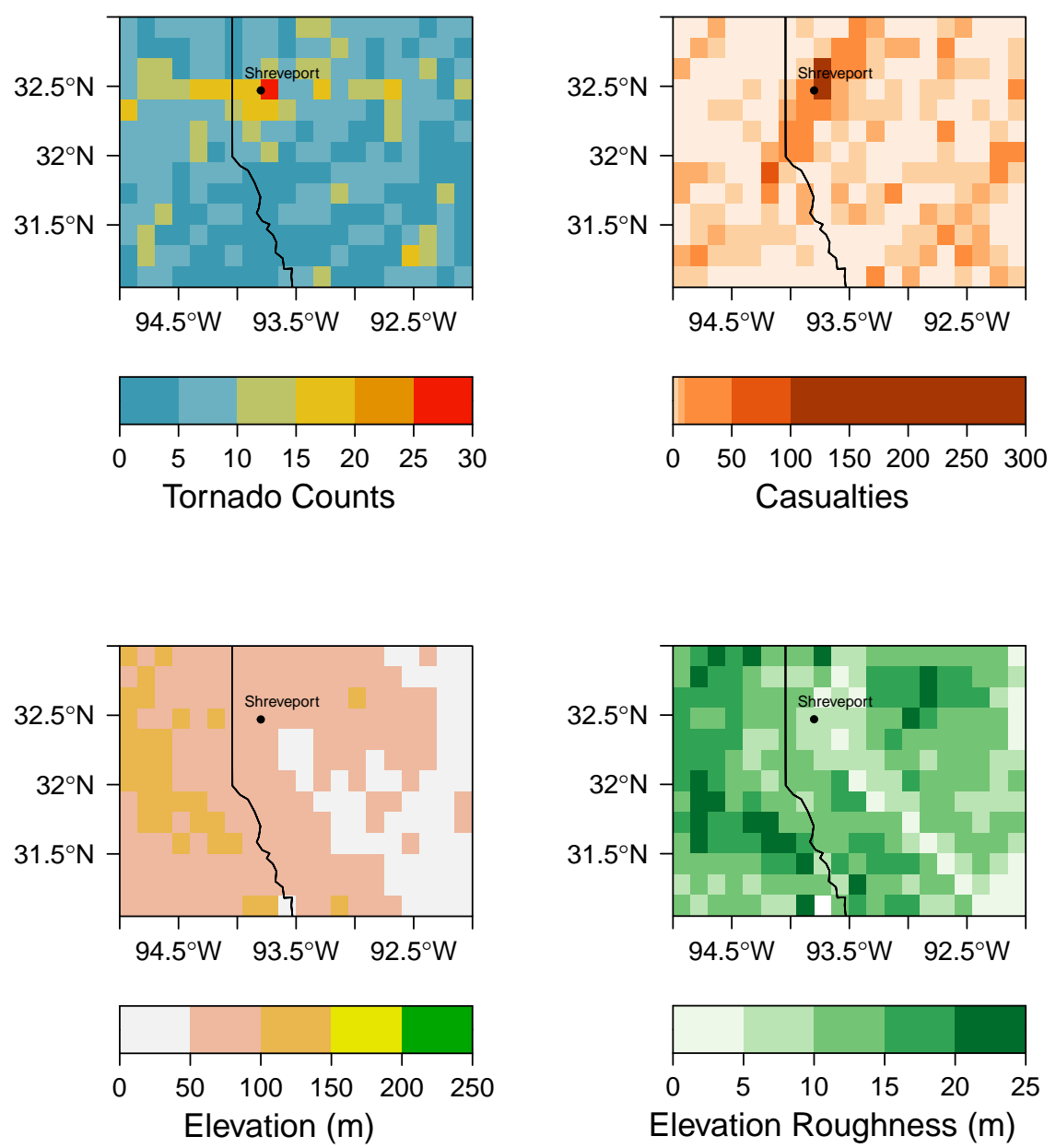

When considering all cells in the domain, the relationship between tornado 281 counts and elevation differs from the relationship between tornado counts and 
elevation roughness. The Pearson's correlation coefficient between the number of tornadoes and elevation per cell is .11 $[(-.01, .23), 95 \%$ confidence interval (CI), p-value $=.07]$ which suggests that, generally, the number of tornadoes slightly increases with elevation. Conversely, the Pearson's correlation coefficient between the number of tornadoes and elevation roughness per cell is $-.05[(-.17, .07) 95 \%$ CI, p-value $<.05]$, which suggests that, generally, the number of tornadoes slightly decreases with elevation roughness.

As a means of investigating the relationship between elevation, elevation roughness, and tornado casualties, we calculate the number of casualties per cell using areal interpolation of the path area of each tornado and the area of the tornado path that was contained in each cell (Fig. 3). When considering all cells in the domain, the Pearson's correlation coefficient between the number of tornado casualties and elevation per cell is $-.08[(-.19, .05), 95 \% \mathrm{CI}, \mathrm{p}$-value $=.22]$ and the Pearson's correlation coefficient between the number of tornado casualties and elevation roughness per cell is $-.18[(-.30,-.06), 95 \% \mathrm{CI}, \mathrm{p}$-value $<.05]$. These values indicate that the number of tornado casualties decreases with both elevation and elevation roughness, suggesting that smoother and lower topography increases the chance of a tornado casualty, but not necessarily the chance of a tornado-given the positive relationship between the number of tornadoes and elevation.

To evaluate whether or not the relationship between tornado counts, tornado casualties, elevation, and elevation roughness is more or less pronounced in Shreveport, we limit our analysis to only those grid cells near the city. When considering the cells in the immediate vicinity of Shreveport $\left(93^{\circ}\right.$ and $94.5^{\circ} \mathrm{W}$ longitude and $32^{\circ}$ and $33^{\circ} \mathrm{N}$ latitude), the relationship between tornado counts and elevation mirrors the relationship seen across the larger domain. The Pearson's correlation coefficient between the number of tornadoes and elevation per cell is .02 $[(-.22$, $.25), 95 \% \mathrm{CI}, \mathrm{p}$-value $<.05]$ and the Pearson's correlation coefficient between the number of tornadoes and elevation roughness is $-.35[(-.54,-.13), 95 \% \mathrm{CI}$, pvalue $<.05]$, which suggests that that the number of tornadoes near Shreveport slightly increases with elevation and decreases with elevation roughness.

Similar to the larger domain, the number of tornado casualties near Shreveport increases as elevation and elevation roughness decreases with a Pearson's correlation coefficient between the number of tornado casualties and elevation per cell at $-.26[(-.47,-.03), 95 \% \mathrm{CI}, \mathrm{p}$-value $<.05]$ and the Pearson's correlation coefficient between the number of tornado casualties and elevation roughness at $-.35[(-.54$, $-.13), 95 \%$ CI, p-value <.05]. Given the magnitude of the Pearson's correlation coefficients, it is somewhat clear that the relationships between tornado counts, tornado casualties, elevation and elevation roughness are stronger in the immediate vicinity of Shreveport than they are in the larger domain.

\section{Mobile Homes}

Mobile homes are an established vulnerability metric in tornado casualty events (Boruff et al., 2003; Ashley, 2007; Strader and Ashley, 2018; Fricker and Elsner, 2019; Ash et al., 2020). Owing to the quality of building materials and low wind load requirements, mobile homes are the site of many tornado casualties throughout the Mid-South and Southeast U.S. With this in mind, we investigate whether 
the presence of mobile homes in and around Shreveport is a main driver of tornado casualty events using data from the 1990, 2000, and 2010 decennial Census at the tract-level (Figure 4).

Fig. 4 Number and percentage of mobile homes of census tracts within $30 \mathrm{~km}$ of Shreveport. Data from the 1990, 2000, and 2010 decennial Census.
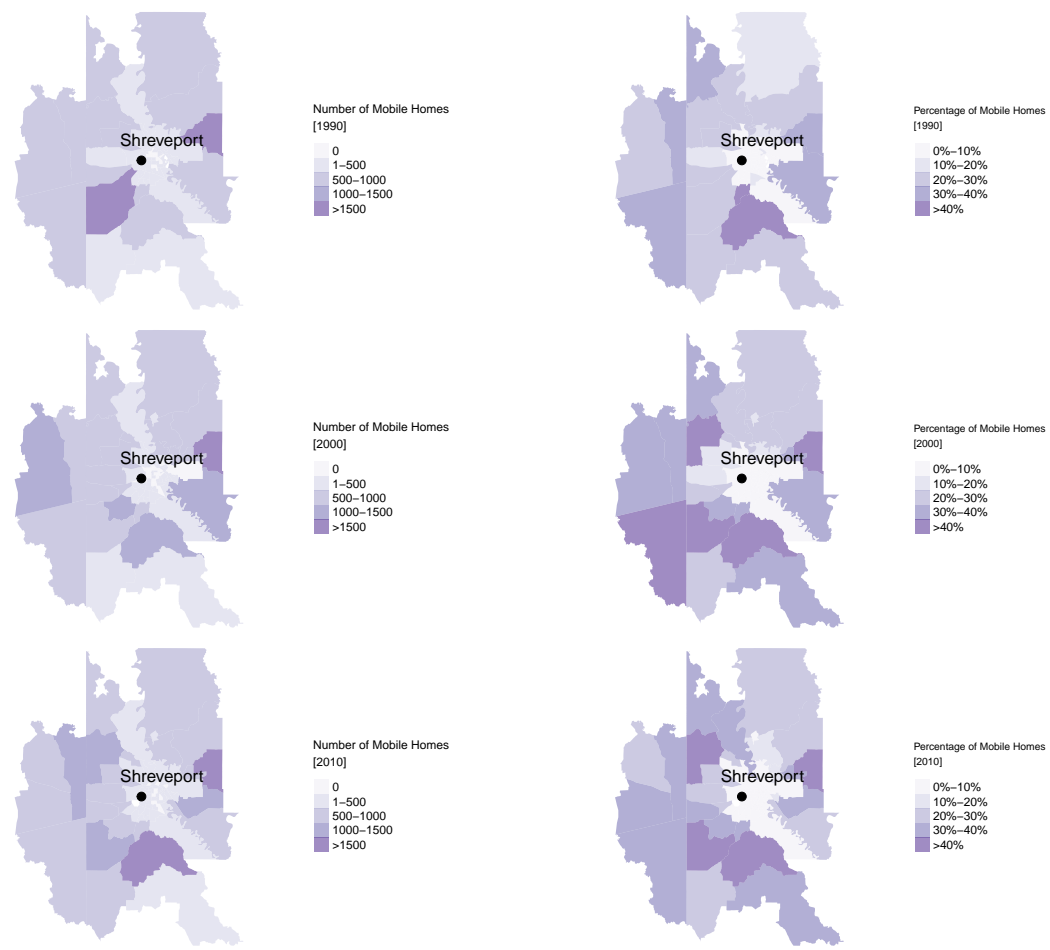

From 1950-2019, 159 Shreveport-area census tracts were impacted by a tornado. The average number of mobile homes in these tracts is 290 with a median number of mobile of mobile homes at 59 and an inter-quartile range between 4 and 545 . The average percentage of mobile homes in these tracts is $12 \%$ with a median percentage of mobile homes at $3 \%$ and an inter-quartile range between $.2 \%$ and $24 \%$. When compared to the state of Louisiana, it is clear that Shreveport-area census tracts, on average, have both a higher total number of mobile homes and a lower total percentage of mobile homes relative to the rest of the state. For example, in 1990, the average number of mobile homes in the Shreveport area was 196, while the state average was 181 . In 2000 , the average number of mobile homes in the Shreveport area was 231, while the state average was 218 and in 2010, the average number of mobile homes in the Shreveport area was 257, while the state average was 224. The average percentage of mobile homes in the Shreveport area tracts in 1990 was $7.8 \%$, while the state average was $11 \%$. In 2000 , the average percentage of mobile homes in the Shreveport area tracts was $10 \%$, while the state average was $12 \%$, and in 2010 , the average percentage of mobile homes in the 
Shreveport area tracts was $11 \%$, while the state average was $12 \%$. This relationship suggests that while Shreveport may have a relatively high number of mobile homes, this housing stock does not make up a relatively large percentage of total homes (i.e. Shreveport has a lower built vulnerability to tornadoes than the state average).

Discourse on the proper use of mobile home variables in reference to tornadoes is typically divided between research concerning the prediction and understanding of the relationship between tornadoes and casualties (Simmons and Sutter, 2011; Fricker and Elsner, 2019) and research concerning the description and identification of risk and vulnerabilities related to tornadoes and mobile homes (Ashley, 2007; Strader and Ashley, 2018). To test which mobile home variable (i.e. number of mobile homes and percentage of mobile homes) is the most useful in advancing knowledge of tornado casualties in Shreveport, we compare the correlation coefficients of each mobile home variable and the number of casualties.

When considering all census tracts that were impacted by a tornado in Shreveport over the period, the relationship between the number of casualties and the number of mobile homes or the percentage of mobile homes per tract is weak. For all tracts impacted by tornadoes, the Pearson's correlation coefficient between the number of casualties and the number of mobile homes per tract is .16 [ $(-.10$, $0.41), 95 \%$ confidence interval $(\mathrm{CI}), \mathrm{p}$-value $=.26]$ and the Pearson's correlation coefficient between the number of casualties and the percentage of mobile homes per tract is $.15[(-.03, .32), 95 \% \mathrm{CI}$, p-value $=.11]$. For all tracts impacted by casualty-producing tornadoes, the Pearson's correlation coefficient between the number of casualties and the number of mobile homes per tract is .16 [ $(-.10, .41)$, $95 \% \mathrm{CI}, \mathrm{p}$-value $=.22]$ and the Pearson's correlation coefficient between the number of casualties and the percentage of mobile homes per tract is $.15[(-.11, .26)$, $95 \% \mathrm{CI}$, p-value $=.26]$. As such, while it is well-known that the presence of mobile homes increases the probability of a casualty in a tornado, it does not appear that mobile homes are a large driver of tornado casualties around Shreveport - though this finding is not statistically significant.

\section{Barksdale Bubble}

The Barksdale Bubble - the presence of a weather manipulation force that protects the Barksdale Air Force Base (Barksdale AFB) from the impacts of extreme weather - is one of the most widely talked-about urban legends in the Shreveport area (Whatley, 2017). While the origins of the legend are not completely known, it is assumed that the Barksdale Bubble became part of the area's vernacular after the installation of a Doppler Radar at the Barksdale AFB airport in 1995. The legend has grown as screenshots of radar reflectively images show rain around the Shreveport area and while Barksdale AFB appeared clear (Brightman, 2021). Theories about the radar images of the Barksdale Bubble range from an urban micro-climate to a military artificial power eliminating rain and storms. In reality, the Barksdale Bubble can be explained through radar limitations, which captures rain in the upper atmosphere, which may - or may not - be reaching the surface, ultimately leading to radar images of rain around Barksdale AFB, but not in its immediate vicinity. 
To test whether or not the Barksdale Bubble exists in any invisible manneras there is no physical buffer around the Barksdale AFB - we investigate tornado casualty rates for those that impact the Barksdale AFB (6 km radius) and those that impact the rest of the Shreveport area (30 km radius). From 1950-2019, there were 8 tornadoes that impacted the Barksdale AFB for an annual rate of .11 tornadoes per year. The 8 tornadoes resulted in 101 casualties, with 19 fatalities and 82 injuries, which corresponds to a casualty rate of 12.6 , a fatality rate of 2.38 , and an injury rate of 10.2 per tornado. Over the same period, the Shreveport area was impacted by 108 tornadoes resulting in 683 casualties, 29 fatalities, and 654 injuries, which corresponds to a casualty rate of 6.3 , a fatality rate of .26 , and an injury rate of 6.1. This means that, historically, tornadoes impacting the Barksdale AFB cause twice as many casualties, nine times as many fatalities, and 1.7 times as many injuries as those impacting the city.

The historical context of tornado casualty rates for those tornadoes impacting the Barksdale AFB is a compelling argument suggesting that those around the Barksdale AFB might be at higher risk to being a tornado casualty than those in other Shreveport areas. However, the Barksdale Bubble is a newer urban legend likely originating around the installation of a Doppler Radar in 1995. To test whether or not the Barksdale Bubble exists in any invisible manner since 1995, we investigate tornado casualty rates for those that impacted the Barksdale AFB and those that impacted the rest of the Shreveport area over the period 19952019. From 1995-2019, there were only 2 tornadoes that impacted the Barksdale AFB for an annual rate of .02 tornadoes per year. The 2 tornadoes resulted in 3 casualties, with 1 fatality and 2 injuries, which corresponds to a casualty rate of 1.5 , a fatality rate of .5 , and an injury rate of 1 per tornado. Over the same period, the Shreveport area was impacted by 38 tornadoes resulting in 167 casualties, 8 fatalities, and 159 injuries, which corresponds to a casualty rate of 4.4 , a fatality rate of .21, and an injury rate of 4.2. So, since the installation of the Doppler Radar at the Barksdale AFB, tornado occurrence and casualty rates are lower than other Shreveport areas. This reduction in tornado impacts may be helping to fuel the narrative that the Barksdale AFB has some artificial power in reducing rain and storms.

\section{Dixie Alley}

One of the most active regions of the U.S. with respect to tornado occurrence is the Great Plains - known colloquially as "Tornado Alley." The creation of the term "Tornado Alley" dates back to the 1950s and its popularity is likely the result of Great Plains-centered tornado research and the picturesque nature of Great Plains tornadoes moving across the landscape in movies like the Wizard of $O z$. The Plains, however, are not the only high-risk areas of the country when considering tornadoes. Much of the Mid-South and Southeast U.S. is at nearly constant threat to the negative impacts of tornadoes in a region known colloquially as "Dixie Alley." While the term "Dixie Alley" is problematic for a number of reasons, its impact on how people understand and respond to tornadoes in the Mid-South and Southeast might be useful for making sense of casualty rates in the region.

To test whether or not an understanding of "Dixie Alley" plays a role in the tornado casualty landscape of Shreveport, we investigate tornado casualty rates 
for those that occurred before and after 1971 - the year National Severe Storms Forecast Center Director Allen Pearson - coined the term (Gagan et al., 2010). From 1950-1971, there were 23 tornadoes that resulted in 108 casualties, with 18 fatalities and 90 injuries. This corresponds to a casualty rate of 4.7 , a fatality rate of .78, and an injury rate of 3.9 per tornado. From 1972-2019, there were 85 tornadoes that resulted in 575 casualties, with 11 fatalities and 564 injuries, which corresponds to a casualty rate of 6.8 , a fatality rate of .13 , and an injury rate of 6.63 per tornado. This means the casualty rate of tornadoes impacting Shreveport is higher for tornadoes occurring after the creation of the term "Dixie Alley" than for tornadoes occurring before the creation of the term.

It is possible, however, that the influence knowledge of "Dixie Alley" has on tornado casualties in Shreveport can be linked to more modern interpretations and uses of the term. One such modern use of "Dixie Alley" can be seen in the aftermath of the Super Outbreak of 2011 - a tornado outbreak occurring primarily in the Mid-South and Southeast U.S. that resulted in over 300 casualties. When considering tornado casualty rates for those occurring before and after 2011, it is clear that the people of Shreveport have fared far better in tornado casualty events taking place after the devastating 2011 season than tornado casualty events taking place before. In fact, the casualty rate of tornadoes before the Super Outbreak of 2011 is over 68 times higher at 7.5 than the casualty rate of tornadoes after the Super Outbreak of 2011 at .12.

Regression analysis was performed on these data to establish whether or not the difference in casualty rates before and after the creation of the term "Dixie Alley" (1971) and before and after the Super Outbreak of 2011 (2011) is statistically significant. When accounting for improvements in detection and warning-done so with the inclusion of a yearly trend term - we found a slightly significant difference ( $p$-value $=.09$ ) in casualty rates before and after 1971 , but no significant difference in casualty rates before and after 2011. In both regressions, we found a magnitude effect on our coefficient consistent with the empirical results, which we believe provides some support for statistical inference to be taken - without absolute scientific truth identified.

\section{Redlining}

Facing a housing shortage during the Great Depression, President Franklin Delano Roosevelt created an agency as part of the New Deal stimulus efforts, called the Home Owners' Loan Corporation (HOLC) - housed under the Federal Home Loan Bank Board - to increase the U.S. housing stock (Harriss, 1951). The HOLC - in conjunction with local real estate leaders - assigned grades to residential neighborhoods to reflect "mortgage security," that would become visible in color-coded maps. These neighborhood grades ranged from A-minimal risk for banks and other mortgage lenders - to D-hazardous risk for banks and other mortgage lenders.

Along with the graded maps, the HOLC provided area descriptions to help to organize the data they used to assign the grades. These descriptions and data included the neighborhood's quality of housing, the recent history of sale and rent values, and the racial and ethnic identity and class of local residents. Together, the created maps and documentation provided the foundation for the set of rules 
that dominated real estate practice for nearly a century. Perhaps, unsurprisingly, the process of identifying and grading neighborhoods was largely carried out by middle-to-upper-class white men, which resulted in a segregation of housing opportunity, where affluent and mostly white neighborhoods were graded more favorable than working-class - or poor - and mostly minority neighborhoods. The result of this grading process was redlining - or the suppression of mortgage financing for people of marginalized racial, ethnic, and economic standing (Nelson et al., 2022).

The historical connection between redlining and natural hazard impacts are obvious. Without the ability to secure mortgage financing, many neighborhoods described as hazardous continue to exist with inadequate housing stock relative to the impacts of hazards, including floods, heat waves, and wind storms. Beyond the built environment, many neighborhoods described as hazardous continue to be inhabited by racially, ethnically, and economically marginalized communities. This drives further hazard vulnerability.

To test if any relationship between redlining and tornado casualties exists in Shreveport, we compare the casualty rates for different graded neighborhoods in the city (Fig. 5). Using areal interpolation, the path area of each tornado segmentthe area of the tornado path that was contained in a HOLC grade neighborhoodswas combined with data on the number of casualties to distribute casualty numbers across each neighborhood. For example, if $40 \%$ of the total tornado path area impacted a designated A neighborhood, while the other $60 \%$ impacted a designated $\mathrm{C}$ neighborhood, $40 \%$ of the casualties were attributed to the A neighborhood and $60 \%$ of the casualties were attributed to the $\mathrm{C}$ neighborhood. These attributed casualties were then summed and evaluated by each neighborhood designation, resulting in a total number of casualties per neighborhood.

Over the period 1950-2019, there were 11 tornadoes and 10 casualty-producing tornadoes ( $45 \%$ of the total casualty-producing tornadoes) that impacted at least one designated neighborhood, resulting in 446 casualties with 4 fatalities and 442 injuries. When broken down by neighborhood designation, the lowest ranking neighborhoods (e.g. C and D) experienced far higher casualty rates than the higher ranking neighborhoods (e.g. A and B). In fact, over the period, neighborhoods designated as D had, by far, the highest tornado casualty rate at 23.9 , followed by neighborhoods designated as $\mathrm{C}$ at 12.7 , neighborhoods designated as $\mathrm{B}$ at 7 , and neighborhoods designated as A at 4.6 (Fig. 6).

\section{Discussion and Conclusions}

Risk factors associated with tornado casualties at the national - or regionallevel are generally well established. For example, tornado casualties in the United States often increase with an increase in the strength of the tornado, the number of people within the damage path, the number or percentage of mobile homes, and the number of elderly individuals within the damage path (Bohonos and Hogan, 1999; Simmons and Sutter, 2005, 2008, 2009; Ashley, 2007; Donner, 2007; Dixon and Moore, 2012; Ashley et al., 2014; Fricker et al., 2017a; Lim et al., 2017; Elsner et al., 2018b). Less known are risk factors associated with tornado casualties at the community level. In response to this fact, here we present a placed-based analysis of tornado casualties in Shreveport, Louisiana as a means of evaluating 
Fig. 5 Home Owners' Loan Corporation map of Shreveport-area neighborhoods. Redrafted from the Mapping Inequality Project (https://dsl.richmond.edu/panorama/redlining/).

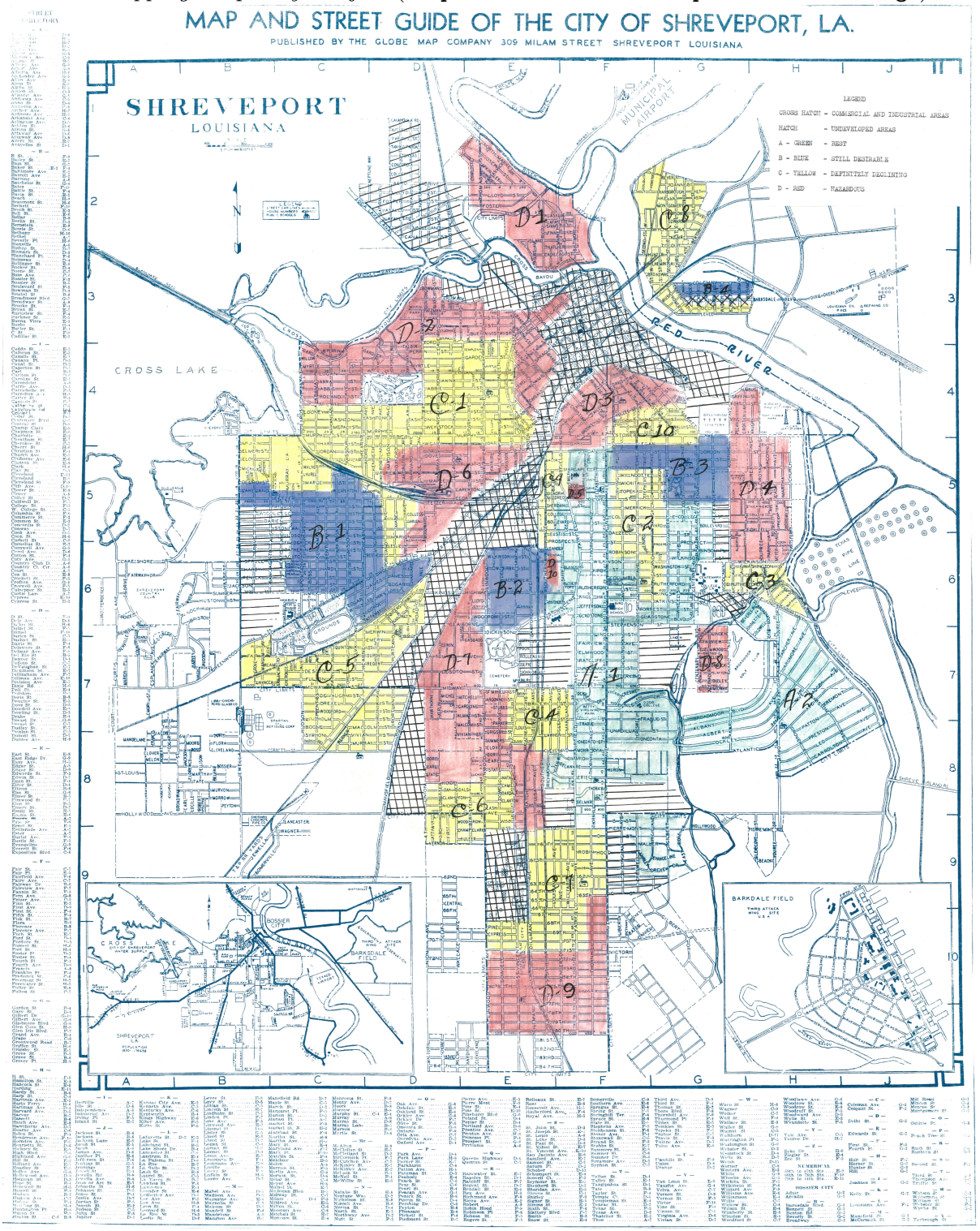

the potential impact several physical and social systems have on tornado casualty rates in the area.

This work is limited by the quality of the tornado reports. That said, because Shreveport has been a populated city for the entirety of the modern record-since 1950 - we do not feel the data are susceptible to the population bias found in the literature (Anderson et al., 2007; Elsner et al., 2013). We also do not feel the use 
Fig. 6 Tornado casualty rates by Home Owners' Loan Corporation neighborhood designations.

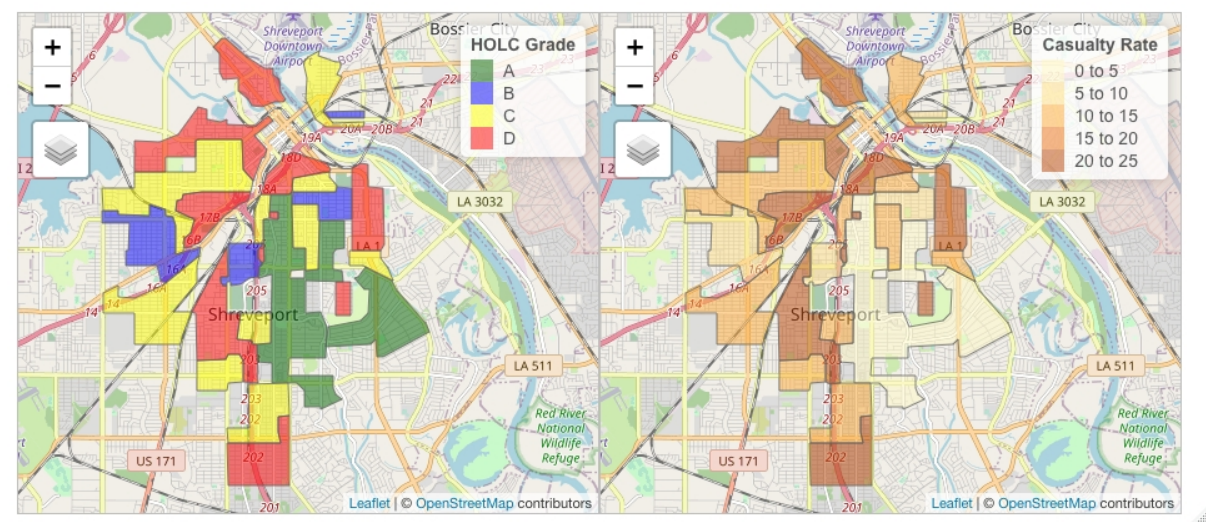

of a straight line path has any quantifiable influence on our results, as Fricker (2020b) has shown individual tornado characteristics are similar between modeled paths and actual paths - those found in the NWS Damage Assessment Toolkit.

Shreveport is an area identified as highly vulnerable and susceptible to large tornado casualty events in recent research (Fricker and Elsner, 2019; Fricker, 2020a). Tornadoes impacting the city are 2.2 times as long, 1.5 times as wide, and 2.6 times as powerful as the national average, which is likely a driving force behind a per-tornado casualty rate that is well above the national average under any definition - whether all tornadoes or only casualty-producing tornadoes - of the tornado casualty rate. But, we know the tornado casualty landscape of any place is more complex than the physical intensity of the tornadoes that impact it. Other factors - both physical and social, in nature - will play a role in how many casualties are seen in each tornado casualty event.

One potential factor related to tornado casualties in Shreveport is the underlying terrain. Tornado frequency and intensity is often affected by the physical landscape it traverses (Karpman et al., 2013; Jagger et al., 2015; Elsner et al., 2016). Smoother and lower topography is more conducive to increased air inflow that produces tornadoes than rougher and higher topography. When comparing tornado counts and casualties to both elevation and elevation roughness, it appears that the number of tornadoes or tornado casualties increases with a decrease in elevation and elevation roughness. Thus, the smoother and lower terrain - areas to the south and east of the city - are more prone to tornadoes and tornado casualties than the rougher and higher terrain - areas to the west of the city.

Mobile homes are another potential factor related to tornado casualties in Shreveport. All else being equal, residents of mobile homes are at a higher risk and vulnerability to being a tornado casualty than residents of permanent homes (Boruff et al., 2003; Ashley, 2007; Strader and Ashley, 2018; Fricker and Friesenhahn, 2021). In Shreveport, however, mobile homes do not appear to be a large driving force behind the rate of tornado casualties, as the Pearson's correlation coefficient between the number or tornado casualties and the number or percentage of mobile homes per tract does not exceed .15. This is notable, because it 
means the high per-tornado casualty rate in Shreveport is likely due to some other combination of factors that may - or may not-be prevalent in other regions of the country.

Thinking beyond widely used and countable variables - those that can be found in the decennial census or similar survey programs - Shreveport is home to an urban legend known as the Barksdale Bubble - the presence of a weather manipulation force that protects the Barksdale AFB from the impacts of extreme weather. Historically, tornadoes impacting the Barksdale AFB cause twice as many casualties as those impacting the city of Shreveport. And although the difference in size between the Barksdale Bubble and Shreveport area-which is roughly five times as large - explains the difference in annual rates of tornadoes, it does not explain the difference in casualty rates. Since the installation of the Doppler Radar at the Barksdale AFB in 1995, casualty rates of tornadoes impacting the base are lower than other Shreveport areas, which may help fuel the narrative that the Barksdale AFB is protected from rain and storms.

While the Barksdale Bubble narrative obviously cannot be explained by some non-existent weather altering machine, the story itself can speak to a geographic understanding of the area's weather effects and how powerful institutions and wealthy, empowered individuals within society can locate themselves in prime geographic locations while relegating marginalized communities to less desirable, more hazardous locations. What if these stories were analyzed not as comical episodes of impossible conspiracy theories and instead analyzed as local knowledge of how unevenly our populations are distributed across local landscapes? In short, the Barksdale Bubble may speak to the uneven vulnerability to risk that marginalized populations are positioned with due to their geographic location in the region and how the powerful and privileged have historically resided on less vulnerable land.

Given its geographic location, Shreveport is associated with a region of the country known colloquially as "Dixie Alley." Unlike the traditionally understood "Tornado Alley," which includes much of the Great Plains, "Dixie Alley" includes areas of the Mid-South and Southeast U.S. Similar to the Barksdale Bubble, historically, tornadoes impacting Shreveport after the creation of the term "Dixie Alley" resulted in higher casualty rates than tornadoes impacting Shreveport before the creation of the term. However, when considering more modern and widespread use of the term - in the aftermath of Super Outbreak of 2011 - casualty rates of tornadoes impacting the city before the Super Outbreak of 2011 are much higher than the casualty rates of tornadoes impacting the city after the Super Outbreak of 2011.

Like many cities in the United States, Shreveport was surveyed and graded by the HOLC during the 1930s, ultimately resulting in redlining. When broken down by neighborhood designation, the lowest ranking neighborhoods experienced far higher casualty rates than the higher ranking neighborhoods. Indeed, neighborhoods designated as D experienced a casualty rate over five times (5.2) higher than neighborhoods designated as A. This indicates that formerly redlined neighborhoods are significantly more vulnerable to tornadoes than other neighborhoods in the same place.

Taking seriously Smith's (2006) analysis that "there's no such thing as a natural disaster" helps frame an approach that questions why formerly redlined areas of Shreveport suffer from higher casualties that the rest of the city. Taking such socioenvironmental research and theory seriously ask us to go beyond conventional wis- 
dom in explaining such disparate impacts and encourages scholars, instead, to look toward structural, socio-political explanations for why particular communities are positioned with more risk with regards to environmental hazards. Understanding these structural disparities are foundational to providing meaningful interventions that avoid deficit-thinking and center the lives of those most impacted.

It seems reasonable to assume that one explanation for the disparities in Shreveport-area tornado casualties are the historical inequalities that led to geographically positioning marginalized communities in the most vulnerable location for tornado events. For example, tornadoes in the area have been known since the early $20^{t h}$ century to move from the Southwest to the Northeast (Fig. 7) meaning that people located along these paths will most likely encounter more of these storms and, particularly for those west of the city, will have less warning time to react as they are often the first populations to be impacted. The positioning of communities in Shreveport is most likely a legacy of white supremacy as the region's plantations were in the west of the parish. Following the end of slavery, many formerly enslaved persons were pressed back into a quasi-enslaved position of sharecropping (Reid, 1975; Riddle, 1995), where enslaved persons worked the same land they worked during slavery - living on or close to the plantations - which might explain how Black communities became concentrated within the areas most vulnerable to tornadoes and tornado casualties.

Furthermore, the obvious knowledge that locals had and demonstrated through repeated warnings in the newspapers about the path of tornadoes through the region could indicate that those with power and wealth would avoid areas known to have been frequently impacted by severe storms and tornadoes. While much of this is speculation, it is the kind of historical, structural elements that must be investigated further using place-based approaches. Such place-based approaches are necessary to understanding the multi-dimensional, structural and historical legacies that produce our uneven society.

When combined with quantitative methods, these place-based approaches have the ability to create regional-or-local intervention strategies that can reduce the loss of life to tornadoes - or more broadly, all hazards. Including place-based data can provide context to statistical models that controls for local knowledge and histories of those most impacted by the destruction we are trying to predict and mitigate. By taking these knowledges and histories seriously, we can work towards creating more effective and nuanced models that account for and address structural factors often overlooked like redlining, racial histories of development, and socioenvironmental knowledges. And though many statistical models are made with the goal of maximizing the variance explained, we believe that if done properly, the making of responsible theory-driven models - those looking to explain causality or the mechanism underlying the data rather than variance- will be possible. 
Fig. 7 Shreveport Times article describing precautionary measures that should be taken by local residents. Published on 08-05-1885.

\section{THE TORNADO.}

PRECAUTIONARY MEASURES TO BE ADOPTED FOR SAFETY.

Every Man Shoula Construet a "Dug-Out."

- A Place of Sufo Itetrent-Mów

to Dodge the Funnel-shaped

Aerial Menster.

is the best position in any cellar. If for any reason you can not get to the west wall, taie your position (the next best) face forward against the south wall, but as near the south tvest corner as possible. In case the building is removed from the foundation it will always be carried above and over you, or if torn to pieces, the debris will be instantly removed to the eastwaid. Under no circuinstances, whether in a building or a cellar, take a position in a northeast corner, in au east room, or against an east wall. Remember that the tornado cloud invariably moves in a northeasterly direction. 


\section{Declarations}

\section{Funding}

The authors did not receive support from any organization for the submitted work.

\section{Conflicts of interest/Competing interests}

The authors report no conflicts of interest.

\section{Availability of data and material}

All available public data sets are linked in the manuscript.

\section{Code availability}

The code used to produce the tables and graphs is available at https://github.com/ tfricker/Tornado-Political-Ecology.

\section{Acknowledgements}

We thank the three anonymous reviewers for their recommendations and feedback on an earlier draft.

\section{References}

Alexander DE (2007) Misconception as a barrier to teaching about disasters. Prehospital and Disaster Medicine 22(2):95-103

Anderson CJ, Wikle CK, Zhou Q (2007) Population influences on tornado reports in the United States. Weather and Forecasting 22:571-579

Ash KD, Egnoto MJ, Strader SM, Ashley WS, Roueche DB, Klockow-McClain KE, Caplen D, Dickerson M (2020) Structural Forces: Perception and Vulnerability Factors for Tornado Sheltering within Mobile and Manufactured Housing in Alabama and Mississippi. Weather, Climate, and Society 12(3):453-472, DOI 10.1175/wcas-d-19-0088.1, URL https://doi.org/10.1175/wcas-d-19-0088.1

Ashley W (2007) Spatial and temporal analysis of tornado fatalities in the United States: 1880-2005. Weather and Forecasting 22:1214-1228

Ashley WA, Krmenec AJ, Schwantes R (2008) Vulnerability due to nocturnal tornadoes. Weather and Forecasting 23:795-807

Ashley WS, Strader S, Rosencrants T, Krmenec AJ (2014) Spatiotemporal changes in tornado hazard exposure: The case of the expanding bull's-eye effect in chicago, illinois. Wea Climate Soc 6(2):175-193, DOI 10.1175/wcas-d13-00047.1, URL http://dx.doi.org/10.1175/WCAS-D-13-00047.1

Bluestein H (2000) A Tornadic supercell over elevated, complex terrain: The Divide, Colorado, storm of 12 July 1996. Monthly Weather Review 128:795-809

Bluestein HB (2013) Severe Convective Storms and Tornadoes. Springer, Berlin, Heidelberg

Bohonos JJ, Hogan DE (1999) The medical impact of tornadoes in north america. The Journal of Emergency Medicine 17(1):67-73 
Bolin B (2007) Race, class, ethnicity, and disaster vulnerability. In: Handbook of Disaster Research, Springer New York, pp 113-129, DOI 10.1007/978-0-38732353-4_7, URL https://doi.org/10.1007/978-0-387-32353-4_7

Boruff B, Easoz J, Jones S, Landry H, Mitchem J, Cutter S (2003) Tornado hazards in the United States. Climate Research 24:103-117, DOI 10.3354/cr024103, URL https://doi.org/10.3354\%2Fcr024103

Box GEP, Hunter JS, Hunter WG (2005) Statistics for experimenters, 2nd edn. Wiley Series in Probability and Statistics, Wiley-Blackwell, Chichester, England

Brightman A (2021) Barksdale bubble: Explaining the legend of the 'weather manipulation device' protecting barksdale air force base. URL https://www.ksla.com/2021/04/05/barksdale-bubble-explaining-legendweather-manipulation-device-protecting-barksdale-air-force-base/

Brooks HE, Doswell CA, Kay MP (2003) Climatological estimates of local daily tornado probability for the United States. Wea Forecasting 18:626-640

Bullard RD (1990) Dumping in Dixie: Race, Class, and Environmental Quality. Westview Press, Boulder, CO

Cutter SL, Boruff BJ, Shirley WL (2003) Social vulnerability to environmental hazards. Social Science Quarterly 84(2):242-261, DOI 10.1111/1540-6237.8402002, URL https://doi.org/10.1111\%2F1540-6237.8402002

Davies-Jones RP (1973) The dependence of core radius on swirl ratio in tornado simulator. J Atmos Sci 30:1427-1430

Davis LP, Museus SD (2019) What is deficit thinking? an analysis of conceptualizations of deficit thinking and implications for scholarly research. NCID Currents 1(1), DOI 10.3998/currents.17387731.0001.110, URL https://doi.org/ 10.3998/currents.17387731.0001.110

Dixon RW, Moore TW (2012) Tornado vulnerability in Texas. Weather, Climate, and Society 4:59-68

Donner WR (2007) The Political Ecology of Disaster: An Analysis of Factors Influencing U.S. Tornado Fatalities and Injuries, 1998-2000. Demography 44(3):669-685, DOI 10.1353/dem.2007.0024, URL https://doi.org/10.1353\% 2Fdem.2007.0024

Dunn LB, Vasiloff SV (2001) Tornadogenesis and operational considerations of the 11 August 1999 Salt Lake City tornado as seen from two different Doppler radars. Weather and Forecasting 16:377-398

Ellis K, Mason LR, Hurley K (2020) In the Dark: Public Perceptions of and National Weather Service Forecaster Considerations for Nocturnal Tornadoes in Tennessee. Bulletin of the American Meteorological Society 101(10):E1677E1684, DOI 10.1175/bams-d-19-0245.1, URL https://doi.org/10.1175/bamsd-19-0245.1

Elsner JB, Michaels LE, Scheitlin KN, Elsner IJ (2013) The decreasing population bias in tornado reports. Weather, Climate, and Society 5:221-232

Elsner JB, Fricker T, Widen HM, Castillo CM, Humphreys J, Jung J, Rahman S, Richard A, Jagger TH, Bhatrasataponkul T, Gredzens C, Dixon PG (2016) The relationship between elevation roughness and tornado activity: A spatial statistical model fit to data from the central great plains. Journal of Applied Meteorology and Climatology 55(4):849-859, DOI 10.1175/jamc-d-15-0225.1, URL https://doi.org/10.1175/jamc-d-15-0225.1

Elsner JB, Fricker T, Berry WD (2018a) A model for U.S. tornado casualties involving interaction between damage path estimates of population density 
and energy dissipation. Journal of Applied Meteorology and Climatology DOI 10.1175/jamc-d-18-0106.1, URL https://doi.org/10.1175/jamc-d-18-0106.1

Elsner JB, Ryan E, Strode G (2018b) Structural property losses from tornadoes in florida. Weather, Climate, and Society 10(2):253-258, DOI 10.1175/wcas-d17-0055.1, URL https://doi.org/10.1175/wcas-d-17-0055.1

Fricker T (2020a) Evaluating tornado casualty rates in the United States. International Journal of Disaster Risk Reduction 47:101535, DOI 10.1016/ j.ijdrr.2020.101535, URL https://doi.org/10.1016/j.ijdrr.2020.101535

Fricker T (2020b) Tornado-level estimates of socioeconomic and demographic variables. Natural Hazards Review 21(3):04020018, DOI 10.1061/(asce)nh.15276996.0000379, URL https://doi.org/10.1061/(asce)nh.1527-6996.0000379

Fricker T, Elsner JB (2019) Unusually devastating tornadoes in the United States: 1995-2016. Annals of the American Association of Geographers DOI 10.1080/ 24694452.2019 .1638753

Fricker T, Friesenhahn C (2021) Tornado fatalities in context: 1995-2018 DOI 10.31235/osf.io/fpy3g, URL https://doi.org/10.31235/osf.io/fpy3g

Fricker T, Elsner JB, Jagger TH (2017a) Population and energy elasticity of tornado casualties. Geophysical Research Letters 44:3941-3949, DOI 10.1002/ 2017gl073093, URL https://doi.org/10.1002\\%2F2017g1073093

Fricker T, Elsner JB, Mesev V, Jagger TH (2017b) A dasymetric method to spatially apportion tornado casualty counts. Geomatics, Natural Hazards and Risk 8(2):1768-1782, DOI 10.1080/19475705.2017.1386724, URL https://doi.org/ $10.1080 / 19475705.2017 .1386724$

Gagan JP, Gerard A, Gordon J (2010) A historical and statistical comparison of "Tornado Alley" to "Dixie Alley.". National Weather Digest 34:145-155

Grove M, Ogden L, Pickett S, Boone C, Buckley G, Locke DH, Lord C, Hall B (2017) The legacy effect: Understanding how segregation and environmental injustice unfold over time in baltimore. Annals of the American Association of Geographers 108(2):524-537, DOI 10.1080/24694452.2017.1365585, URL https://doi.org/10.1080/24694452.2017.1365585

Hand D (2019) What is the purpose of statistical modelling? Issue 1 DOI 10.1162/ 99608f92.4a85af74, URL https://doi.org/10.1162/99608f92.4a85af74

Harriss CL (1951) Front matter, history and policies of the home owners' loan corporation. In: History and Policies of the Home Owners' Loan Corporation, NBER, pp 24-0

Hoekstra S, Klockow K, Riley R, Brotzge J, Brooks H, Erickson S (2011) A preliminary look at the social perspective of warn-on-forecast: Preferred tornado warning lead time and the general public's perceptions of weather risks. weather, climate, and society 3(2):128-140

Hoffman JS, Shandas V, Pendleton N (2020) The effects of historical housing policies on resident exposure to intra-urban heat: A study of 108 US urban areas. Climate 8(1):12, DOI 10.3390/cli8010012, URL https://doi.org/10.3390/ cli8010012

Jagger TH, Elsner JB, Widen HM (2015) A statistical model for regional tornado climate studies. PLoS ONE 10(8):e0131876

Karpman D, Ferreira MAR, Wikle CK (2013) A point process model for tornado report climatology. Statistics 2:1-8

Klockow KE, Peppler RA, McPherson RA (2014) Tornado folk science in alabama and mississippi in the 27 april 2011 tornado outbreak. GeoJournal 79(6):791- 
804, DOI 10.1007/s10708-013-9518-6, URL https://doi.org/10.1007/s10708013-9518-6

Krocak MJ, Allan JN, Ripberger JT, Silva CL, Jenkins-Smith HC (2021) An analysis of tornado warning reception and response across time: leveraging respondent's confidence and a nocturnal tornado climatology. Weather and Forecasting DOI 10.1175/waf-d-20-0207.1, URL https://doi.org/10.1175/waf-d20-0207.1

Leslie FW (1977) Surface roughness effects on suction vortex formation: A laboratory simulation. J Atmos Sci 34:1022-1027

Lewellen WS (1962) A solution for 3 dimensional vortex flows with strong circulation. Journal of Fluid Mechanics 14:420-432

Lim J, Loveridge S, Shupp R, Skidmore M (2017) Double danger in the double wide: Dimensions of poverty, housing quality and tornado impacts. Regional Science and Urban Economics 65:1-15, DOI 10.1016/j.regsciurbeco.2017.04.003, URL https://doi.org/10.1016/j.regsciurbeco.2017.04.003

Mason LR, Ellis KN, Winchester B, Schexnayder S (2018) Tornado warnings at night: Who gets the message? Weather, Climate, and Society 10(3):561568, DOI 10.1175/wcas-d-17-0114.1, URL https://doi.org/10.1175/wcas-d$17-0114.1$

McKay J, Devlin M (2015) 'low income doesn't mean stupid and destined for failure': challenging the deficit discourse around students from low SES backgrounds in higher education. International Journal of Inclusive Education 20(4):347-363, DOI 10.1080/13603116.2015.1079273, URL https://doi.org/ 10.1080/13603116.2015.1079273

Molina MJ, Timmer RP, Allen JT (2016) Importance of the gulf of mexico as a climate driver for u.s. severe thunderstorm activity. Geophysical Research Letters 43(23), DOI 10.1002/2016gl071603, URL https://doi.org/10.1002/ $2016 g 1071603$

Namin S, Xu W, Zhou Y, Beyer K (2020) The legacy of the home owners' loan corporation and the political ecology of urban trees and air pollution in the united states. Social Science \& Medicine 246:112758, DOI 10.1016/j.socscimed.2019.112758, URL https://doi.org/ 10.1016/j.socscimed.2019.112758

Nelson RK, Winling L, Marciano R, Connolly N (2022) Mapping inequality. URL https://dsl.richmond.edu/panorama/redlining/\#loc=5/39.1/ -94.58\&text=intro

Neyman J (1939) On a new class of "contagious" distributions, applicable in entomology and bacteriology. The Annals of Mathematical Statistics 10(1):35-57, DOI 10.1214/aoms/1177732245, URL https://doi.org/10.1214/ aoms $/ 1177732245$

Prociv KA (2012) Terrain and landcover effects of the southern appalachian mountains on the rotational low-level wind fields of supercell thunderstorms. Master's thesis, Virginia Polytechnic Institute and State University

Pulido L (2015) Geographies of race and ethnicity 1. Progress in Human Geography 39(6):809-817, DOI 10.1177/0309132514563008, URL https://doi.org/ $10.1177 / 0309132514563008$

Reid JD (1975) Sharecropping in history and theory. Agricultural History 49(2):426-440, URL http://www.jstor.org/stable/3741281 
Riddle WA (1995) The origins of black sharecropping. The Mississippi Quarterly 49(1):53-71, URL http://www.jstor.org/stable/26475959

Shmueli G (2010) To explain or to predict? Statistical science 25(3):289-310

Simmons KM, Sutter D (2005) WSR-88D radar, tornado warnings, and tornado casualties. Weather and Forecasting 20(3):301-310, DOI 10.1175/waf857.1, URL https://doi.org/10.1175\%2Fwaf857.1

Simmons KM, Sutter D (2008) Tornado warnings, lead times, and tornado casualties: An empirical investigation. Weather and Forecasting 23(2):246-258, DOI 10.1175/2007waf2006027.1, URL https: //doi.org/10.1175\%2F2007waf2006027.1

Simmons KM, Sutter D (2009) False alarms, tornado warnings, and tornado casualties. Weather, Climate, and Society 1(1):38-53, DOI 10.1175/2009wcas1005.1, URL https://doi.org/10.1175\%2F2009wcas1005.1

Simmons KM, Sutter D (2011) Economic and Societal Impacts of Tornadoes. American Meteorological Society, Boston

Smit R (2012) Towards a clearer understanding of student disadvantage in higher education: problematising deficit thinking. Higher Education Research \& Development 31(3):369-380, DOI 10.1080/07294360.2011.634383, URL https: //doi.org/10.1080/07294360.2011.634383

Smith N (2006) There's no such thing as a natural disaster. URL https://items.ssrc.org/understanding-katrina/theres-no-such-thingas-a-natural-disaster/

Strader SM, Ashley WS (2018) Finescale Assessment of Mobile Home Tornado Vulnerability in the Central and Southeast United States. Weather, Climate, and Society 10(4):797-812, DOI 10.1175/wcas-d-18-0060.1, URL https://doi.org/ $10.1175 /$ wcas-d-18-0060.1

US Census Bureau (2019a) 2019 American Community Survey 1-Year Estimates, Table S1101. URL https://data.census.gov/cedsci/

US Census Bureau (2019b) 2019 American Community Survey 5-Year Estimates, Table S1901. URL https://data.census.gov/cedsci/

Verbout SM, Brooks HE, Leslie LM, Schultz DM (2006) Evolution of the U.S. tornado database: 1954-2003. Weather and Forecasting 21:86-93

Weaver SJ, Baxter S, Kumar A (2012) Climatic role of north american low-level jets on u.s. regional tornado activity. Journal of Climate 25(19):6666-6683, DOI 10.1175/jcli-d-11-00568.1, URL https://doi.org/10.1175/jcli-d-11-00568.1

Whatley J (2017) Biggest conspiracy theory surrounding shreveport. URL https: //k945.com/barksdalebubble/ 